\title{
Higher Education Students: Academic Emotions, Consequences and Emotional Regulation Strategies
}

Fátima Leal

Centro de Investigação em Educação e Psicologia

\begin{abstract}
Emotions of academic achievement are important due to the impact they can have on students in learning situations (Harley, Pekrun, Taxer \& Gross, 2019) but, sometimes, higher education students are unaware of what they feel while studying, how they regulate these emotions and also how much they affect themselves (Leal \& Grácio, 2019). Objectives: This work aims to understand: the perception of higher education students about their academic emotions, their consequences for themselves; and comprehend what emotional regulation strategies they use to deal with what they feel while studying. Methods: 48 higher education students were interviewed. 24 boys and 24 girls. Content analysis was made with NVivo12 software. Results: Results suggest that students consider that what they feel while studying affect them personally, positively and negatively, regarding to: cognition; affective aspects; regulation of their motivation; interpersonal relationships and on their personal change. To deal with their emotions, they use cognitive, metacognitive, motivational and socio-environmental organization regulation strategies. Some of them were also found by other authors (e.g. Chaleta, Grácio \& Efklides, 2011). Conclusions: It is really important to create spaces and moments where students can reflect, understand and share their emotions, their consequences and regulation strategies to deal with them. Higher education contexts should promote this kind of moments where students can increase their emotional regulation strategies.
\end{abstract}

Keywords: Higher education; Students; Academic emotions; Consequences; Emotional regulation strategies 